\title{
Gluten-free industry is healthy, but is the food?
}

$\mathrm{T}$ he market for gluten-free products is booming, and there have never been more food options for people who avoid the grain protein for health reasons. That doesn't mean, however, that all glutenfree foods are healthy.

"There's a lot of misinformation," says Kathy Smart, an Ottawa, Ontariobased chef and nutritionist who specialized in gluten-free food. Smart was diagnosed with celiac disease more than 20 years ago. "Whenever you follow the money, you'll find out there's some sort of fiscal reason people are saying what they're saying."

Of course, markets grow to meet demand, so it should come as no surprise that retailors are stamping "gluten-free" on more food products, healthy or not. After all, consumer interest shows no signs of slowing. In September, for example, about 9000 people are expected to pay $\$ 12-\$ 15$ each to visit the Metro Toronto Convention Centre in Ontario for the Gluten Free Expo. The event, which features gluten-free product vendors and high-profile speakers, will also be held in Vancouver, British Columbia, and Calgary, Alberta.

The expo started as a charity event a couple of years ago to gather glutenfree donations for food banks. While volunteering at a food bank, event creator Margaret Dron realized there were few donations suitable for people with celiac disease. She organized an event with 38 vendors, and people could attend with the donation of a glutenfree item. Dron expected 500 people to attend, but about 3000 showed up.

Realizing how large the market is for gluten-free products and education, Dron, who has a background in business and marketing strategy, upsized the event into the Gluten Free Expo, which still collects donations for food banks.

"It's a knowledge-driven market," says Dron, explaining that as more people learn about celiac or gluten intolerance, interest in buying gluten-free grows.

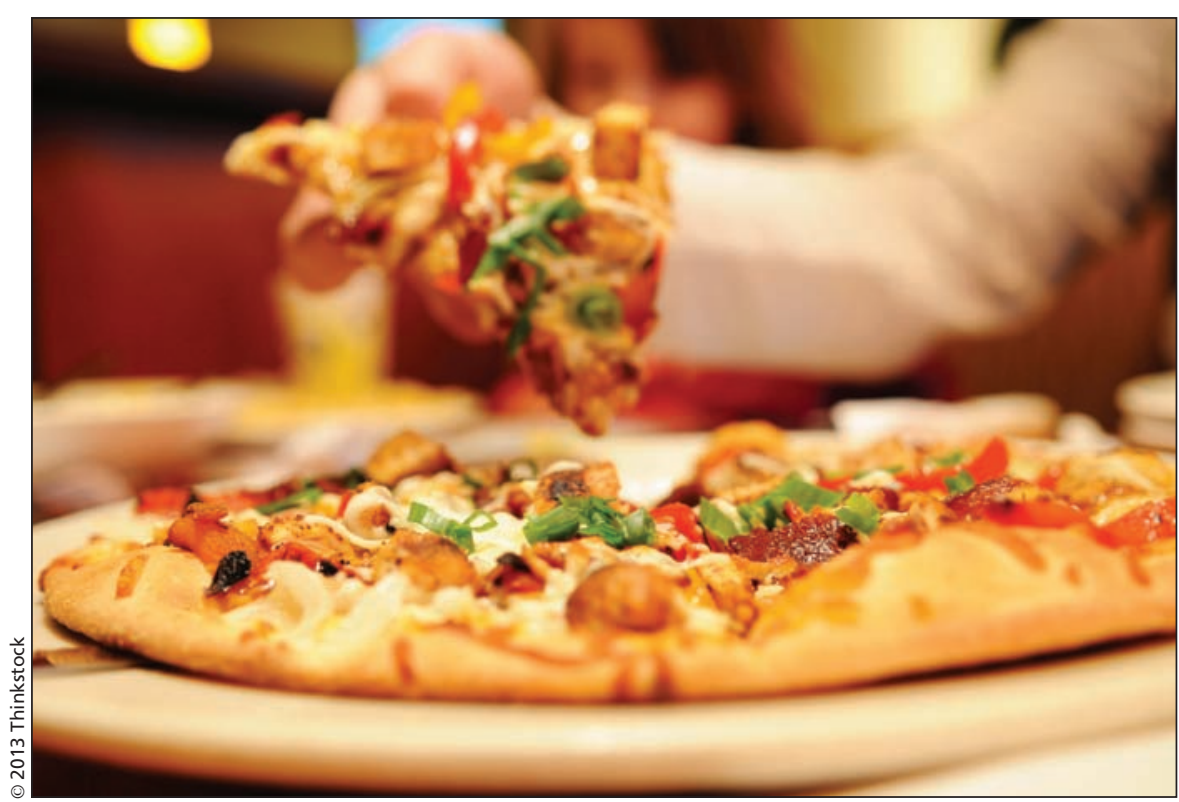

Think that gluten-free pizza is the healthier choice? Not necessarily, warn nutritionists.

And growing interest leads to growing sales. In 2010, global gluten-free sales totalled $\$ 2.5$ billion, a figure that more than doubled by 2012, according to a recent paper on gluten-related disorders (BMC Med 2012;10:13). "Gluten-free" is also Canada's top restaurant menu health claim, ahead of "low-calorie," says market-research firm NPD Group. Canada even has a marketing agency devoted entirely to businesses with gluten-free products.

Some people buy these products for medical reasons. They may have celiac disease, which the Canadian Celiac Association estimates affects 1 in 133 people, or gluten intolerance. Many people seem to be embracing gluten-free diets to lose weight and improve health.

But the belief that avoiding gluten automatically leads to weight loss is a major misconception, says Alexandra Anca, a Toronto dietitian. In fact, she finds the opposite to be true. People with celiac will often gain weight as their intestines repair and they are able to absorb more nutrition from their food.

People eating gluten-free may also gain weight because they are consuming more calories. Mainstream gluten-free flours such as rice, tapioca, potato and sorghum are higher on the glycemic index than wheat, containing more carbohydrates and calories. Gluten-free baking also tends to contain more fat and sugar to make up for the lack of gluten.

Boston Pizza, for instance, offers individual-sized "GlutenWise" pizzas that have about 720 calories, compared to the 500 or so calories in its regularcrust pizza. The GlutenWise pizza is also higher in fat, sodium and sugar.

Besides having more calories, gluten-free packaged goods tend to be low in fibre and unfortified. People on gluten-free diets therefore need to get dietary fibre, folic acid, calcium and B vitamins from other sources, says Anca. In general, says Smart, people seeking to live gluten-free should get "back to the basics," like anyone else attempting to live a healthier lifestyle.

"Healthy, real food, like fresh chicken, eggs, whole veggies, nuts, seeds and legumes don't have to make nutrition claims," she says. "But you don't make a lot of money saying, 'Just eat real food." - Catherine Cross, CMAJ

CMAJ 2013. DOI:10.1503/cmaj.109-4555 